\title{
A TRAJETÓRIA DO PERDÃO NA OBRA DE HANNAH ARENDT
}

\author{
Adriano Correia*
}

\begin{abstract}
O objetivo deste artigo é examinar o desenvolvimento do tema do perdão na obra de Hannah Arendt, principalmente nos textos da década de 1950. Ao longo da década a autora modifica substancialmente sua compreensão da relação do perdão com o cristianismo e progressivamente situa o perdão, assim como a promessa e o poder, no centro de sua análise da ação e de suas fragilidades. Realizamos uma análise bibliográfica que percorre obras publicadas e textos inéditos e buscamos realizar uma síntese conceitual das várias características do perdão na obra da autora a partir do exame da relação da ação com a necessária reconciliação com sua imprevisibilidade.
\end{abstract}

Palavras-chave: Perdão. Ação. Reconciliação. Hannah Arendt. Paul Ricoeur.

\section{INTRODUÇÃO}

Há muitas coisas que devemos carregar, como um feixe de lenha nos ombros.

Friedrich Hölderlin

O tema do perdão aparece em $A$ condição humana, de Hannah Arendt, em um movimento breve e decisivo ao fim do capítulo sobre a ação, o conceito que sob muitos aspectos pode ser tido por centro de toda a obra. Ao longo do capítulo Arendt insiste no caráter revelador da ação, no vínculo entre ação e identidade, na espontaneidade do agente, na sua necessidade de articulação com seus pares para levar a cabo seus empreendimentos. Caracteriza a ação como não-soberana, precisamente porque é livre e se dá em uma teia de relações constituídas pelas iniciativas e reações de outros agentes. A não-soberania dos agentes sobre os desdobramentos de suas

* Universidade Federal de Goiás. Faculdade de Filosofia. Av. Esperanca, SN, Campus Samambaia - Conj. Itatiaia. Cep: 74690-900. Goiânia - Goiás - Brasil. adrianocorreia@ufg.br http://orcid.org/0000-0001-6819-1681 ações e a consequente imprevisibilidade delas é um traço fundamental do domínio dos assuntos humanos e faz com que haja uma demanda permanente de reconciliação, uma vez que a não soberania de um agente espontâneo implica em que ele provoque ofensas, por imprevidência, por fragilidade ou pela "obscuridade do coração humano" - "a incapacidade do homem para confiar em si mesmo e para ter fé absoluta em si próprio (o que é a mesma coisa) é o preço que os seres humanos pagam pela liberdade" (Arendt, 2016, p. 302).

Dentre as várias hipóteses de Arendt sobre a capacidade do perdão de ser um remédio para os efeitos das transgressões e para as rupturas entre os agentes na teia de relações, cabe destacar a simetria entre perdão e vingança como possibilidades de reação não compulsória à ofensa. Focaremos nossa atenção, dentre outros temas, na assimetria que se instala no percurso do perdão entre ofensor e ofendido com o pedido de perdão - pedido que é indispensável, para Arendt: tanto uma porta escancarada para a recomposição dos fios rompidos pela ofensa quanto um caminho ancho para uma vingança redobrada. No plano do espa- 
ço comum, a assimetria no percurso do perdão pode se apresentar para o ofendido como momento oportuno para extrair vantagens públicas na exposição fragilizada do ofensor arrependido, como uma forma proveitosa de reparação vingativa sem reconciliação.

Arendt considera essa assimetria como desigualdade em suas primeiras anotações sobre o tema do perdão, no início dos anos 1950, mas não a retoma em $A$ condição humana, onde temos a formulação mais acabada do perdão como ação redentora. Exploraremos suas considerações iniciais em diálogo com a obra de Paul Ricoeur, para quem a assimetria do perdão é um tema fundamental, com vistas a considerar a sua extraordinária potência, mas também sua fragilidade como remédio para a imprevisibilidade da ação.

\section{O PERCURSO DO PERDÃO EM HANNAH ARENDT}

É bem conhecida e debatida a seção de A condição humana (1958) em que Arendt trata da irreversibilidade da ação e do poder de perdoar. O percurso da reflexão de Arendt que culmina nesta seção breve e veemente parece remontar ao início da década de 1950, quando Arendt retornou de uma longa viagem à Europa, a primeira após a Segunda Guerra Mundial, e é marcado por descontinuidades e inflexões decisivas na compreensão do perdão pela autora. Este percurso pode ser precariamente retraçado em sua obra inédita e tem início precisamente tendo como um dos temas centrais a assimetria do perdão, ou o que ela chama de destruição radical da igualdade.

A primeira anotação de Hannah Arendt do volume de mais de mil páginas de seu Diário de pensamento, editado e publicado há pouco mais de uma década, tem como tema o perdão. Na ocasião em que concluía para publicação a obra As origens do totalitarismo ela se detém no exame das articulações entre injustiça, perdão, vingança e reconciliação.
Arendt pondera que a injustiça a nós cometida é como um fardo que carregamos sobre as costas, ao contrário do que concebe o conceito cristão de pecado, consoante ao qual "a injustiça vem dentro do próprio indivíduo, como se o pecado permanecesse dentro de nós mesmos e envenenasse o organismo inteiro, já afetado potencialmente, de modo que são requeridos a graça e o perdão não para nos des-carregar, mas para purificar-nos" (Arendt, 2002, p. 3 [I, Jun-1950, 1], grifos no original).

Entre os cristãos, insiste Arendt, o perdão só pode, em última instância, vir de Deus, e em penúltima só pode se dar entre indivíduos radicalmente separados entre si qualitativamente.

\begin{abstract}
O gesto de perdão destrói tão radicalmente a igualdade, e com isso o fundamento das relações humanas, que, propriamente, depois de tal ato já não seria possível relação alguma. O perdão entre homens não pode significar algo diferente do seguinte: renúncia a vingar-se, calar, e passar ao largo; e por si mesmo isso significa, por princípio, despedir-se. A vingança, pelo contrário, permanece sempre próxima do outro e o relacionamento simplesmente não termina. O perdão, ou o que normalmente se chama assim, é realmente apenas um simulacro; nele um se afirma como superior e o outro exige algo que os homens não podem nem retirar nem conceder uns aos outros. O simulacro consiste em que um, que se apresenta sem carga, carrega aparentemente o peso das costas de outro (Arendt, 2002, p. 3 [I, jun-1950, 1]).
\end{abstract}

O mais notável nessa sua remota ocupação com o tema é sua insistência em separar perdão de reconciliação, por um lado, e seu rechaço do perdão cristão como signo da concepção de uma natureza humana corrompida e irredimível em uma medida humana, por outro. Ao perdão Arendt opõe a reconciliação, que consiste em, por assim dizer, assumir o que recaiu sobre nós, na medida em que "o que se reconcilia carrega voluntariamente o peso que o outro leva de qualquer modo. Isso significa que restabelece a igualdade. Assim, a reconciliação é exatamente o contrário do perdão, que estabelece a desigualdade" (Arendt, 2002, p. 4 [I, jun-1950, 1], grifos no original). Trata-se do tormento da desproporção entre profundidade 
da falta e a altura do perdão considerado por Paul Ricoeur, mas lamentavelmente este é um tema ao qual Arendt não retornará.

Em 2000, quase nonagenário, Paul Ricoeur publicou a obra $A$ memória, a história, $o$ esquecimento. Marcadamente abrangente e aberta em suas conclusões, a obra articula os três conceitos mencionados no título a partir de uma fenomenologia da memória, de uma epistemologia da história e de uma hermenêutica da condição histórica, alinhavados pela problemática comum da representação do passado (cf. Ricoeur, 2014, p. 18). O epílogo do livro, seção que mais nos interessa aqui, acrescenta à tríade mencionada no título o tema do perdão. Intitulada "O perdão difícil” - "nem fácil, nem impossível” - a seção apresenta o perdão como "horizonte comum da memória, da história e do esquecimento" (Ricoeur, 2014, p. 465). O perdão articula a representação do passado com a fenomenologia do homem falível e do homem capaz, levada a cabo ao longo de décadas por Ricoeur em sua obra.

Em sua discussão sobre o perdão, Ricoeur estabelece um diálogo estreito com vários pensadores, como Derrida e Jaspers, mas também com Arendt. Ele tende a concordar com Derrida, quando este afirma, em diálogo crítico com Arendt, que "o perdão dirige-se ao imperdoável, ou não é. Ele é incondicional, ele é sem exceção e sem restrição. Ele não pressupõe um pedido de perdão" (Ricoeur, 2014, p. 474). Como veremos, a compreensão de Arendt segue em outra direção, mas há um ponto decisivo na análise de Ricoeur que dialoga involuntariamente com as primeiras considerações de Arendt sobre o perdão: trata-se do que Ricoeur chama de assimetria do perdão, do desequilíbrio entre a profundidade da falta e a altura do perdão. Isto torna o perdão difícil, mais uma vez, na medida em que, mais que a reconciliação e o alívio do fardo da culpa e do ressentimento, ele tem de encontrar uma equação a partir de uma situação de profunda desigualdade.

Com efeito, não pode haver perdão a não ser que se possa imputar a alguém um ato e que esse alguém assuma como suas as ações que são levadas a sua conta (cf. Ricoeur, 2014, p. 467), assim como as consequências dela, na medida ponderada da imputação em um contexto de pluralidade. Esta assunção da responsabilidade na vinculação do agente ao ato, pelo ofendido e por ele mesmo, é o reconhecimento de uma falta que tende a afetar a potência de agir do ofensor e a memória apaziguada do ofendido, mas é também a via privilegiada de uma liberação de ambos do ciclo do atrelamento compulsório a uma ocorrência passada que sem a reconciliação não cessará de urdir implicações no presente e no futuro.

Para compreender a possível equação do perdão a partir de uma radical assimetria entre a profundidade da falta e da culpa e a altura do perdão, Ricoeur reflete sobre o que chama de economia do dom e sobre a afinidade entre o perdão e o dom em sua dimensão de reciprocidade em uma troca que não é comercial. Trata-se de ultrapassar a notável assimetria entre quem dá e quem recebe a partir do modelo arcaico da troca, que vincula as obrigações de dar, de receber e de retribuir (cf. Ricoeur, 2014, p. 486-487), reinterpretado sob a forma de um dar que supõe, em vez da retribuição, um simplesmente receber. Esta dádiva, para Ricoeur, não institui uma demanda de reciprocidade nem esmaga o beneficiário em uma profunda assimetria instaurada por uma dívida insolúvel. Ainda que subsista como um enigma, a assimetria "entre o muito alto espírito do perdão e o abismo da culpabilidade" pode ter uma resposta avançada, pensa Ricoeur: "dar honrando o beneficiário é a forma de que se reveste, no plano da troca, a consideração" (Ricoeur, 2014, p. 489) - ou, para Arendt, o respeito, como veremos.

A solidariedade do ofendido com o fardo do dano só é possível se tivermos em conta "a gratidão fundamental pelo dado", ou a gratidão por tudo que é como é, o avesso do ressentimento e permite uma ativa reconciliação com o dado elementar de que não sou meu próprio criador, ainda que muito do que me constitui esteja sob minha responsabilidade - uma ativa 
reconciliação que busca romper com a compreensão da existência como devedora e culpável por não ter criado a si mesma (Cf. Arendt, 2002, p. 4 e 815 [I, jun-1950, 1 e "Kant”]). ${ }^{1}$ Ainda que seja "ineludivelmente escasso", o que ocorre na reconciliação assim compreendida, seguramente, não se trata de um sucesso aparente, como no caso do perdão, na medida em que não promete o impossível, isto é, a mútua liberação. Trata-se antes da compartilha solidária do fardo da injustiça, baseada na deliberada disposição do ofendido para assimilar o que lhe sobreveio e para reatar com o ofensor os vínculos rompidos - "decidem-se a ser corresponsáveis, mas sob nenhuma circunstância co-culpados" (Arendt, 2002, p. 7 [I, jun-1950, 1]). Trata-se, ao mesmo tempo, de se reconciliar com uma realidade, de aceitar ou recusar assimilar um estado de coisas e a reposição de um vínculo - algo que só pode ser motivado pela gratidão pelo dado e pelo desejo de conservação do estar junto a outros, que Arendt por vezes chamou de amizade, amor ou respeito, como considerarei adiante.

Por outro lado, é a atitude de calar e passar ao largo, de desviar o olhar que forma um par com a reconciliação. São, assim, disposições claramente positivas ou ativas, antagônicas à mera reação do perdão ou da vingança. A solidariedade não é do compartilhamento da mácula, mas a da não soberania dos agentes. No "intento híbrido de conseguir que o feito deixe de estar feito, algo pretendido tanto $\infty$ pelo que perdoa quanto pelo que pede perdão" $\stackrel{\infty}{8}$ (Arendt, 2002, p. 6 [I, jun-1950, 1]), tem lugar đิ o puramente "re-ativo", antagônico à ação.

' 1 "A gratidão não é uma virtude cristã, não está presente no cristianismo, mas antes é suplantada pela resignação

à vontade de Deus, ou seja, é na verdade substituída pela

๓ superação do ressentimento contra Deus. Distintamente

$>$ da resignação, a gratidão é livre, não tem nada a ver com o

i fato de servir a Deus. Do ressentimento do escravo contra o

Senhor divino, como percebeu Nietzsche, surge o ressen-

$\stackrel{\pi}{\perp}$ timento mais profundo contra toda a realidade, na medida

స్ em que ela está dada e não foi fabricada pelo homem. E daí

- brota o ressentimento contra o feito por outros homens, ou

seja, contra o mundo inteiro. Mas a desconfiança do cris-

ช tianismo ante a natureza é também uma falta de gratidão;

aí surge uma desconfiança contra o que é subtraído à sobe-

rania humana. A liberdade cristã é hostil à natureza, pois

significa soberania, independência da natureza ou domínio sobre ela” (Arendt, 2002, p. 10-11 [I, jun-1950, 6]).
O avesso da gratidão pelo dado e da reconciliação com o ocorrido, que se traduz no responder por si inclusive no que concerne ao que propriamente não controlamos, é a cumplicidade cristã baseada no pecado original. Com efeito, em vez de compartilhar da culpa com base no pecado original, que implica a cumplicidade consistente em dizer "também poderíamos tê-lo feito" ou "também isto é humano", temos a solidariedade resultante da reconciliação via partilha da injustiça acontecida. Dá-se, assim, a reconciliação entre agentes que admitem que o fracasso e a ofensa são inseparáveis de uma vida ativa, mas não a definem em última instância.

Esta reconciliação, que não promete dissolver o fardo da injustiça nem exonerar o ofensor, mas antes indica a disposição do ofendido para aceitar compartilhar o fardo do ocorrido com ele, é o avesso do perdão, na medida em que restabelece uma igualdade na compartilha do fardo. Não está em jogo a cumplicidade com a ofensa pela concepção de uma natureza humana comum degenerada - que exonera por lembrar que poderia ter feito o mesmo, porque somos todos pecadores e podemos esperar o pior de nós mesmos e dos outros -, mas antes a solidariedade que resulta do fato de que "a reconciliação pressupõe seres humanos que atuam e que podem inclusive cometer injustiças, mas não seres humanos envenenados" (Arendt, 2002, p. 6-7 [I, jun-1950, 1]). Trata-se de uma noção de solidariedade que, assim como o desviar do olhar e despedir-se que é sua alternativa, supõe o juízo e não opera, como a vingança e o perdão, na alternativa entre o castigo e a exculpação cúmplice.

A avaliação do cristianismo como um ressentimento contra uma natureza humana pecadora e como meio de transformação de toda falta ou ofensa em culpa - como se toda ofensa fosse mera atualização desta natureza envenenada pelo pecado - é decisiva para o rechaço inicial do perdão cristão, por Arendt. Esta avaliação é demarcada por um estreito diálogo com Nietzsche, nas anotações nos Diários de pen- 
samento, mas também nos numerosos cursos e conferências ministrados por ela até meados da década de 1950. Ao longo desta década, não obstante, esta sua avaliação se transfigura profundamente e ganha novos contornos.

Em uma anotação de abril de 1951 Arendt ainda separa perdão de reconciliação tendo em conta a assimetria do perdão, mas já estabelece uma distinção decisiva de compreensão entre Jesus de Nazaré e o cristianismo acerca do perdão. Para ela, Jesus não buscava com o perdão exibir a natureza perversa e culpável do ser humano, mas antes banir o ser culpável do mundo dissolvendo "o ser culpável em um mero haver-cometido-injustiça” (Arendt, 2002, p. 69 [III, abr-1951, 22]) ou perpetrado uma ofensa. Pouco tempo depois insiste em que a própria essência ou natureza humana é indefinida e desconhecida, havendo então um irredutível elemento de insegurança na ação, de modo que "não é possível nenhuma ação sem perdão recíproco (que em política se chama reconciliação). Assim como em Jesus, o perdão se baseia no conhecimento de que nós nunca podemos saber inteiramente o que fazemos" (Arendt, 2002, p. 303-304 [XIII, jan-1953, 17], grifo no original).

Em dois momentos em 1953 Arendt já aponta na direção da breve síntese desse longo período de reflexão que se articula enfim em $A$ condição humana:

o perdão, a misericórdia e a reconciliação não revogam coisa alguma, mas prolongam a ação iniciada, embora em uma direção que não lhe era inerente. A grandeza destas formas de comportamento está em que interrompem o automatismo do que 'não-revogável' (Nicht-rückgängig-zu-Machenden). São a autêntica re-ação espontânea. Aí radica sua produtividade. Instauram um novo começo no interior de uma ação cuja execução já havia começado (Arendt, 2002, p. 312 [XIII, fev-1953, 30]). ${ }^{2}$

\footnotetext{
${ }^{2}$ No texto “Compreensão e política”, publicado em 1954 Arendt observa que o perdão é "uma das maiores capacidades humanas e talvez a ação humana mais ousada, na medida em que tenta o aparentemente impossível, a saber, desfazer o que foi feito, e consegue criar um começo quando tudo parecia ter chegado ao fim" (Arendt, 2008, p. 330-331).
}

Já temos então a indicação do caráter ativo ou produtivo do perdão, que representa uma profunda alteração em sua posição inicial, assim como adiante suprimirá qualquer referência positiva à compaixão, enfatizando sempre antes a solidariedade dos agentes. Pouco tempo depois, em junho de 1953, altera mais uma vez um aspecto fundamental de sua posição inicial quando afirma que

\begin{abstract}
o princípio propriamente político do amor cristão reside no perdão. Com efeito, isto não pode ser deslocado a alma do indivíduo, para isso se requer sempre outro. Eu posso dominar a mim mesmo (...), mas ninguém pode perdoar a si mesmo. Nesse sentido o cristianismo levou realmente a sério a pluralidade dos homens (Arendt, 2002, p. 376 [XVI, jun-1953, 7]).
\end{abstract}

Acrescenta ainda, pouco tempo depois, por fim, que "todo o ensinamento de Jesus, do perdão à graça, pretendia somente mostrar aos homens que eles mesmos podem conseguir que o feito não esteja feito, e isto é precisamente em que consiste a graça de Deus" (Arendt, 2002, p. 504 [XX, nov-1954, 44]).

Se considerarmos a elaboração das articulações entre irreversibilidade e perdão em $A$ condição humana, como o faremos, é notável o quanto os elementos conservados dessa análise - como o caráter reativo da vingança e o caráter ativo da reconciliação - são amplamente suplantados pelos traços de ruptura, claramente no que tange ao significado e à dignidade do perdão. Todos os elementos nietzschianos da recusa do perdão cristão com vistas ao passar ao largo, desviar a vista ou despedir-se são elididas. As razões dessa profunda mudança de posição, notadamente no que tange à avaliação do cristianismo, ou ao menos dos ensinamentos de Jesus de Nazaré, talvez possa ser compreendida pelo progressivo distanciamento da crítica nietzschiana ao cristianismo, que tanto a ocupou no início dos anos 1950, mas infelizmente não pode ser retraçada passo a passo em sua obra inédita ou publicada.

Esta mudança marcante de compreensão aparece de modo exemplar em um escrito inédito de meados da década de 1950, "A tra- 
dição do pensamento político", editado postumamente em A promessa da política, no qual as experiências do cristianismo primitivo são mencionadas entre as experiências políticas fundamentais. Arendt sustenta que

a tradição do pensamento político se interessa pela pluralidade humana como se ela indicasse apenas a soma total de seres razoáveis que, devido a algum defeito decisivo, são forçados a viver juntos e a formar um corpo político. Mas as três experiências políticas que ficam fora da tradição - a experiência da ação como início de um novo empreendimento na Grécia pré-polis, a experiência da fundação em Roma e a experiência cristã de agir e perdoar como vinculados, isto é, o conhecimento de que quem age tem de estar pronto a perdoar e de que quem perdoa de fato age - têm um significado especial porque permaneceram relevantes para nossa história mesmo tendo sido desconsideradas pelo pensamento político. De um modo fundamental todas elas dizem respeito a um aspecto da condição humana sem o qual a política não seria nem possível nem necessária: o fato da pluralidade humana enquanto distinta da unicidade de Deus, seja ele compreendido como uma 'ideia' filosófica ou como o Deus pessoal das religiões monoteístas (Arendt, 2005, p. 60-61).

Arendt chega a afirmar que talvez a falha mais explícita da tradição do pensamento político em relação às verdadeiras experiências políticas se encontre "no abandono silencioso pela escolástica das experiências políticas centrais do cristianismo primitivo" (Arendt, 2005, p. 56). Ela salienta a ousadia e a singularidade da conclusão de Jesus acerca da incerteza da ação humana. Em vez de duvidar da seriedade dos $\infty$ assuntos humanos devido à falta de controle ठํ. dos agentes sobre suas ações e da mútua dependência dos agentes, como teria feito a tradição do pensamento político e as modernas conside$\dot{2}$ rações das filosofias da história, Jesus teria bus§ે cado na natureza da própria ação humana um ò remédio para os inevitáveis erros de um agente que não pode ser soberano justamente porque  relações constituída pelos agentes.

A grande audácia e o orgulho único desse conceito de perdão como uma relação básica entre os seres humanos não residem na aparente conversão da calamidade da culpa e do erro nas possíveis virtudes da magnanimidade ou da solidariedade. Reside antes no fato de que o perdão tenta o aparentemente impossível, desfazer o que foi feito, e que consegue fazer um novo começo onde começos não pareciam ser mais possíveis. Que os seres humanos não sabem o que eles estão fazendo com relação aos outros, que eles possam pretender o bem e alcançar o mal, e vice versa, e que, não obstante, aspirem na ação a mesma realização da intenção da habilidade técnica (mastership) em sua relação com as coisas naturais materiais tem sido o grande tema da tragédia desde a Antiguidade grega. A tradição nunca perdeu de vista este elemento trágico em toda ação nem foi incapaz de compreender, embora usualmente em um contexto não político, que perdoar está entre as maiores virtudes humanas (Arendt, 2005, p. 58).

A novidade especificamente política dos ensinamentos de Jesus de Nazaré, para Arendt, era justamente a assunção da interconexão entre agir e perdoar como sendo constitutiva da relação entre agentes que vivem em comunidade. Em vez de apelar para uma articulação superior das cegas ações humanas em alguma astúcia ou providência e de rechaçar como absurda uma ação trágica (livre e não soberana), em que o agente não controla os desdobramentos de suas iniciativas, Jesus teria encontrado no perdão o remédio propriamente ativo para lidar com as tribulações de uma ação não soberana em um contexto de pluralidade e inter-relacionamento. A grande virtude desse remédio consistiria em não tomar as tribulações ou constrangimentos como razões para o menoscabo da ação, mas antes em buscar lidar com a cadeia de consequências imprevisíveis que se desenrolam de toda ação, enquanto início, de modo que permitam ao agente em alguma medida desligar-se do que desencadeou, ao menos na medida necessária para, mesmo sem deixar de ser responsável, conservar sua potência de agir. Com efeito,

o ato de perdoar é a única ação estritamente humana que libera a nós mesmos e aos outros da cadeia e do tipo de consequências que toda ação engendra; enquanto tal, o perdão é uma ação que garante a continuidade da capacidade para a ação, para come- 
çar algo novamente, em cada ser humano individual que, sem perdoar e sem ser perdoado, se pareceria com o indivíduo do conto de fadas a quem é concedido um desejo e depois é para sempre punido com a relação desse desejo (Arendt, 2005, p. 59).

Aqui já nos encontramos plenamente no ambiente da articulação dos conceitos e das experiências em $A$ condição humana. No centro da obra, dedicada a "pensar o que estamos fazendo ou pensamos que estamos fazendo no mundo em que passamos a viver" (Arendt, 2016, p. 400; Cf. também p. 6) e a refletir sobre as transformações nas atividades humanas fundamentais ao longo da era moderna, está um exame sobre os traços básicos da atividade da ação, enquanto distinta do trabalho e da fabricação. Enquanto o trabalho é a atividade que busca atender à condição de viventes dos seres humanos e a fabricação cria um mundo artificial de coisas úteis, correspondendo à condição humana da mundanidade, a ação corresponde à pluralidade humana, ao fato de que somos ao mesmo tempo iguais e singulares enquanto humanos, que é ao mesmo tempo sua condição de possibilidade e sua razão de ser (Cf. Arendt, 2016, p. 9).

É característico da ação o fato de que os empreendimentos iniciados pelo agente só podem ser levados a cabo a partir da ação conjunta com outros agentes, do "agir em concerto" que constitui o poder político, como assevera Arendt em uma referência a Burke (Arendt, 1998, p. 526. Cf. também p. 287). Ademais desta interdependência entre os agentes, “como a ação atua sobre seres que são capazes de realizar suas próprias ações, a reação, além de ser uma resposta, é sempre uma nova ação que segue seu curso próprio e afeta os outros" (Arendt, 2016, p. 236), fazendo com que todo agente não apenas não seja senhor dos desdobramentos do que inicia, mas também seja padecente das re-ações que sua ação original provoca. Isto faz com que uma das características marcantes da ação seja sua ilimitabilidade, que faz com que cada agente jamais saiba exatamente o que provocará quando se põe a agir, de modo que além de ilimitada, a ação jamais é realmente previsível, precisamente porque constitui uma teia de relações em que cada agente interfere e desvia as iniciativas de cada outro agente. O remédio para a ilimitabilidade e a imprevisibilidade das ações humanas são as promessas recíprocas que se materializam em acordos, leis e instituições que estabilizam, ainda que de modo provisional, as ações desenroladas no espaço comum, na esfera pública. Precisamente por este caráter da ação em um contexto de pluralidade, a fragilidade é um traço constitutivo dos assuntos humanos, mas também a fonte de sua extraordinária fecundidade, de sua capacidade de engendrar relações sempre novas.

Essa fecundidade se revela de modo mais evidente nos remédios buscados no âmbito da própria ação para as incapacidades dos agentes para controlar os processos desencadeados por meio da ação e para desfazer o que foi feito. Os remédios que redimem a ação dos constrangimentos da irreversibilidade e da imprevisibilidade são as capacidades de perdoar e de prometer, que formam um par, desfazendo os atos do passado e instaurando ilhas de segurança no oceano de incertezas do futuro, e "surgem diretamente da vontade de conviver com os outros na modalidade da ação e do discurso e são, assim, semelhantes a mecanismos de controle instaurados na própria faculdade de iniciar processos novos e intermináveis" (Arendt, 2016, p. 304).

Na caracterização do perdão em $A$ condição humana Arendt tece uma série de considerações, muitas delas pouco desenvolvidas, que são fundamentais para a compreensão de sua análise. (1) Ela sustenta que o perdão, assim como a promessa, só possui realidade em um contexto de pluralidade, uma vez que se baseiam "em experiências que ninguém pode ter consigo mesmo e que, ao contrário, se baseiam inteiramente na presença de outros" (Arendt, 2016, p. 294). Em vista disto, ninguém poderia perdoar a si mesmo - tornaremos a este tema no final do texto. (2) Para Arendt, "o descobri- 
dor do papel do perdão no domínio dos assuntos humanos foi Jesus de Nazaré", e o fato de que ele tenha feito esta descoberta no contexto religioso é menos relevante que o fato de que tenha se dado no âmbito da vida em comum das comunidades cristãs primitivas. A descoberta - e não a invenção ${ }^{3}$ - do perdão por Jesus teria se dado justamente pela experiência política autêntica desta vida comunitária. (3) O dever de perdoar sobre o qual insistiu Jesus tem conexão estreita com o fato de que na vida em comum a ofensa, ao contrário do crime e do mal voluntário,

é uma ocorrência cotidiana, decorrência natural do fato de que a ação estabelece constantemente novas relações em uma teia de relações, e precisa do perdão, da liberação, para possibilitar que a vida possa continuar, desobrigando constantemente os homens daquilo que fizeram sem o saber. Os homens podem ser agentes livres somente mediante essa mútua e constante desobrigação do que fazem; somente com a constante disposição para mudar de ideia e recomeçar pode-se confiar a eles um poder tão grande quanto o de começar algo novo. (Arendt, 2016, p. 297).

Assim, o perdão tem estreita conexão não apenas com a recomposição dos vínculos rompidos entre as pessoas por meio da ofensa, mas também com a conservação da liberdade humana que se realiza na ação. Está no centro, portanto, de toda a vida política, ainda que Arendt não indique com clareza como o perdão pode se manifestar nas instituições da vida política ${ }^{4}$. (4) Em A condição humana, contrariamente a suas primeiras reflexões sobre o perdão nos seus Diários de pensamento, o perdão é compreendido como o exato oposto $\approx$ da vingança, uma vez que esta enreda o agente I. indefinidamente em um processo reativo "que $\dot{2}$

ธิ ${ }^{3}$ Ao contrário do que afirma David Konstan, em Before forgiveness - the origins of a moral idea (2010, p. 112), Arendt jamais afirmou que "a ideia do perdão como uma capa๙ cidade humana começou com Jesus", mas antes que ele I. teria descoberto seu papel central na experiência do viver em comum.

${ }^{4}$ A esse respeito, Paul Ricoeur sustenta "que existe uma assimetria significativa entre o poder perdoar e o poder prometer, como o comprova a impossibilidade de autênticas instituições políticas do perdão" (Ricoeur, 2014, p. 466). inexorável automatismo do processo da ação", ao passo que o perdão é uma reação que conserva algo do caráter original da ação, em sua imprevisibilidade, libertando das consequências da ofensa "tanto o que perdoa quanto o que é perdoado” (Arendt, 2016, p. 298). (5) Em As origens do totalitarismo Arendt conclui suas reflexões indicando que o totalitarismo permitiu que descobríssemos que "existem crimes que os homens não podem punir nem perdoar", na medida em que os que cometeram esses crimes "situam-se além dos limites da própria solidariedade do pecado humano" (Arendt, 1998, p. 410). Esta conexão entre o imperdoável e o impunível reaparece em $A$ condição humana nos seguintes termos: "é, portanto, bastante significativo, um elemento estrutural no domínio dos assuntos humanos, que os homens não sejam capazes de perdoar aquilo que não podem punir, nem de punir o que se revelou imperdoável" (Arendt, 2016, p. 298299). É decisivo aqui tanto a dependência que a nossa capacidade de perdoar tem da nossa aptidão para compreender e julgar - desafiada pelo mal extremo - quanto o fato de que somos capazes de provocar ofensas que "transcendem o domínio dos assuntos humanos e as potencialidades do poder humano, os quais destroem radicalmente sempre que surgem" (Arendt, 2016, p. 299). É uma das fragilidades decisivas da ação, portanto, o fato de que pode desencadear eventos que seus próprios remédios não são capazes de redimir. Os seres humanos podem desencadear coisas que os poderes humanos não podem remover, porque são livres, mas não são soberanos. (6) Para Arendt, o perdão envolve um percurso necessário a ser percorrido pelo ofensor, ao final do qual não resulta qualquer dever de perdoar por parte do ofendido. Ao comentar uma das mais conhecidas falas de Jesus sobre o perdão - "se ele te ofender sete vezes no dia, e sete vezes no dia retornar a ti, dizendo 'me arrependo', tu o perdoarás” (Lucas 17, 3-4) - Arendt observa que o que está em jogo nas palavras chave do texto é a transgressão, o erro ou o fracasso (hamarta- 
nein), o mudar de ideia, ou a manifestação do desejo de "voltar sobre os próprios passos", se fosse possível (metanoein), e a possível liberação ou desobrigação (aphienai). Em vista disto, Arendt se permite retraduzir o trecho nos seguintes termos: " $E$ se ele transgredir contra ti (...) e (...) procurar-te, dizendo: Mudei de ideia, deves desobrigá-lo" (Arendt, 2016, p. 297, nota 98). É decisivo que Arendt assimile este rito do perdão assim descrito e não o conceba como um ato incondicional tanto quanto sua recusa de que o perdão, em seu caráter de ação imprevisível, possa ser um dever. De todo modo, para ela o perdão deve implicar um pedido de perdão do transgressor que indique não apenas arrependimento, mas, na manifestação desejo de não ter cometido a ofensa, a promessa de não repeti-la, no que estiver ao alcance do agente. Por fim, (7) é notório que em suas anotações do início da década de 1950 a reconciliação que ela julga imprescindível seja antes de tudo um reconciliar-se mais com a realidade do ocorrido que com alguém que ofendeu, em respeito ou deferência ao agente (que seria assim desligado do ato e da maldição de se ver reduzido em última instância como pessoa ao dano que causou). Ainda que a reconciliação com a realidade jamais deixe de ser um tema para Arendt, em A condição humana a ênfase recai antes sobre a reconciliação entre quem ofendeu e quem foi ofendido, em respeito ao ofensor, que não é assim identificado com sua ofensa e pode então persistir como agente, para liberar a ambos do ciclo da vingança e para permitir que restabeleçam relações entre si.

\section{CONSIDERAÇÔES FINAIS}

Arendt assevera que "o perdão e a relação que ele estabelece constituem sempre um assunto eminentemente pessoal (embora não necessariamente individual ou privado), no qual o que foi feito é perdoado em consideração a quem o fez" (Arendt, 2016, p. 299, grifos no original) ${ }^{5}$. Esta consideração ela chama de respeito, que é "uma espécie de 'amizade' sem intimidade ou proximidade; é uma consideração pela pessoa desde a distância que o espaço do mundo coloca entre nós, consideração que independe de qualidades que possamos admirar ou de realizações que possamos ter em alta conta" (Arendt, 2016, p. 301). Arendt conecta esta noção de respeito à philia politiké aristotélica, a amizade que subjaz às comunidades políticas e se dá justamente na constituição da interação e do diálogo entre indivíduos que se tomam por iguais, assim como na instauração de um espaço que separa, une e preserva as diferenças. Ela observa que "para os gregos a essência da amizade consistia no diálogo. Sustentavam que só o intercâmbio constante da fala podia unir os cidadãos em uma polis. No diálogo tornavam-se manifestas a importância política da amizade e a humanidade que lhe é própria” (Arendt, 1970, p. 24). Esta amizade traduzida como respeito é uma das manifestações do amor ao mundo que para ela era decisivo para a vida política (Cf. Campillo, 2019, p. 97-107). Ela lembra, em seu ensaio sobre Lessing, que "os gregos chamavam àquela philanthropia, 'amor ao homem', a humanidade (humanness) que se alcança no discurso da amizade, uma vez que ela se manifesta em uma disposição para partilhar o mundo com os outros" (Arendt, 1970, p. 25, grifos meus).

Esta disposição não recusa jamais a prerrogativa de julgar, mas não admite que se possa julgar senão em uma medida humana, mas se solidariza com a não soberania dos agentes, julga com padrões humanos e se recusa a imitar a ira de um Deus todo-poderoso. Na formulação de Paul Ricoeur (2014, p. 501): "sob o signo do perdão, o culpado seria considerado como capaz de outra coisa além de seus delitos e faltas. Ele seria devolvido à sua capacidade de agir, e a ação, à de continuar (...) A

${ }^{5}$ Como comenta Paul Ricoeur (2014, p. 489): "Dar honrando o beneficiário é a forma de que se reveste, no plano da troca, a consideração evocada acima. A reciprocidade do dar e do receber põe fim à assimetria horizontal do dom sem espírito de troca, sob a égide da figura singular de que a consideração passa então a se revestir”. 
fórmula dessa fala libertadora, abandonada à nudez de sua enunciação, seria: tu vales mais que teus atos". Os atos revelam quem alguém é em sua identidade única, mas jamais alguém deveria ter sua dignidade usurpada na identificação de sua personalidade com um ou outro ato fracassado - em um juízo desmedido.

É a isto que Hannah Arendt se refere quando condena o louvor de Brecht a Stálin e manifesta ao mesmo tempo seu respeito pelo poeta. Com efeito, diz ela, "todo julgamento está aberto ao perdão, todo ato de julgar pode se converter num ato de perdão; julgar e perdoar são apenas os dois lados de uma mesma moeda”. Mas enquanto a lei tende a avaliar os atos em desconsideração à pessoa que o cometeu,

O ato de perdoar, pelo contrário, leva a pessoa em consideração; nenhum perdão perdoa o assassinato ou o roubo, mas apenas o assassino ou o ladrão. Sempre perdoamos alguém, nunca algo, e é por isto que as pessoas pensam que apenas o amor pode perdoar. Todavia, com ou sem amor, perdoamos em consideração à pessoa, e ao passo que a justiça exige que todos sejam iguais, a misericórdia insiste na desigualdade - uma desigualdade que implica que todo homem é, ou deveria ser, mais que aquilo que fez ou realizou. (Arendt, 1970, p. 248, grifos no original).

Recebido para publicação em 11 de fevereiro de 2020 Aceito em 27 de junho de 2020.

\section{REFERÊNCIAS}

ARENDT, Hannah. Men in dark times. Nova York: Harvest Book, 1970.

ARENDT, Hannah. Origens do totalitarismo. Trad. Roberto Raposo. São Paulo: Companhia das Letras, 1998.

ARENDT, Hannah. Denktagebuch - 1950 bis 1973. 2 Vol. Ed. Ursula Lutz e Ingeborg Nordmann. Munique: Piper, 2002.

ARENDT, Hannah. The promise of politics. Nova York: Schocken Books, 2005.

ARENDT, Hannah. Compreensão e política (as dificuldades da compreensão). In: Compreender: formação, exílio e totalitarismo (ensaios 1930-1954). Trad. Denise Bottmann. São Paulo: Companhia das Letras, 2008.

ARENDT, Hannah. A condição humana. $13^{\mathrm{a}}$ ed. rev. Trad. R. Raposo. Rev. Téc. A. Correia. Rio de Janeiro: Forense Universitária, 2016.

CAMPILlO, António. El concepto de amor en Arendt. Madri: Abada Editores, 2019.

KONSTAN, David. Before forgiveness: the origins of a moral idea. Nova York: Cambridge University Press, 2010.

RICOEUR, Paul. A memória, a história, o esquecimento. Trad. Alan François et. al., Campinas, SP: Editora da Unicamp, 2014. 536p. 


\section{THE TRAJECTORY OF FORGIVENESS IN THE WORK OF HANNAH ARENDT}

\author{
Adriano Correia
}

The aim of this article is to examine the development of the theme of forgiveness in Hannah Arendt's work, especially in the texts of the 1950s. Throughout the decade, the author substantially modifies her understanding of the relationship of forgiveness with Christianity and progressively places forgiveness, as well as promise and the power at the center of her analysis of the action and its weaknesses. We performed a bibliographic analysis that covers published works and unpublished texts and we seek to carry out a conceptual synthesis of the various characteristics of forgiveness in the author's work from the examination of the relationship of the action with the necessary reconciliation with its irreversibility.

Keywords: Forgiveness. Action. Reconciliation. Hannah Arendt. Paul Ricoeur.

\section{LA TRAJECTOIRE DU PARDON DANS L'OEUVRE D'HANNAH ARENDT}

\author{
Adriano Correia
}

Le but de cet article est d'examiner l'évolution du thème du pardon dans l'œuvre d'Hannah Arendt, notamment dans les textes des années 50. Tout au long de la décennie, l'auteur modifie considérablement sa compréhension de la relation entre le pardon et le christianisme et place progressivement le pardon, ainsi que la promesse et le pouvoir, au centre de son analyse de l'action et de ses faiblesses. Nous avons effectué une analyse bibliographique qui couvre les œuvres publiées et les textes non publiés et nous cherchons à réaliser une synthèse conceptuelle des différentes caractéristiques du pardon dans le travail de l'auteur, basée sur un examen de la relation entre l'action et la nécessaire réconciliation avec son irréversibilité.

Mots-CLÉs: Pardon. Action. Reconciliation. Hannah Arendt. Paul Ricoeur. 
